\title{
Routine Use of Quantitative Disease Activity Measurements among US Rheumatologists: Implications for Treat-to-target Management Strategies in Rheumatoid Arthritis
}

\author{
Jeffrey R. Curtis, Lang Chen, Maria I. Danila, Kenneth G. Saag, Kathy L. Parham, \\ and John J. Cush
}

\begin{abstract}
Objective. The aim of our study was to examine why real-world practices and attitudes regarding quantitative measurements of rheumatoid arthritis (RA) have received limited attention.

Methods. An e-mail survey asked US rheumatologists to self-report on their use of quantitative measurements (metric).

Results. Among 439 respondents, metric rheumatologists (58\%) were more likely to be in group practice and to use tumor necrosis factor inhibitors. The quantitative tools most commonly used were the Health Assessment Questionnaire (35.5\%) and the Routine Assessment of Patient Index Data 3 $(27.1 \%)$. Reasons for not measuring included time needed and electronic availability. Based on simulated case scenarios, providing more quantitative information increased the likelihood that a patient would change to a different disease-modifying antirheumatic drug or biologic.

Conclusion. Routine use of quantitative measurement for patients in the United States with RA is increasing over time but remains low. (First Release November 15 2017; J Rheumatol 2018;45:40-4; doi:10.3899/jrheum.170548)
\end{abstract}

Key Indexing Terms:

RHEUMATOID ARTHRITIS

Treat to target, a strategy advocated by international rheumatology guidelines, entails the use of quantitative disease activity measures to facilitate managing rheumatoid arthritis (RA) $)^{1,2,3,4}$. While there seemingly was consensus as these guidelines were established, attitudes and actual practices of US rheumatologists about treat-to-target and quantitative assessment are difficult to ascertain. Disease registries generally do not provide adequate information on how often rheumatologists collect quantitative arthritis measures because this measurement is a required feature of most physician-based registries. In our study, we report results from a survey of US rheumatologists regarding attitudes, practices, and behaviors about quantitative assessment in RA.

From University of Alabama at Birmingham, Birmingham, Alabama; Baylor Research Institute, Dallas, Texas, USA.

Funding received from the US National Institute of Arthritis and Musculoskeletal and Skin Diseases, P60 AR064172.

J.R. Curtis, MD, MPH, MS, University of Alabama at Birmingham; L. Chen, MD, PhD, University of Alabama at Birmingham; M.I. Danila, $M D, M S c, M S P H$, University of Alabama at Birmingham; K.G. Saag, MD, MSc, University of Alabama at Birmingham; K.L. Parham, BA, University of Alabama at Birmingham; J.J. Cush, MD, Baylor Research Institute. Address correspondence to Dr. J.R. Curtis, University of Alabama at Birmingham, 510 20th St. South, Birmingham, Alabama 35294, USA. E-mail:jrcurtis@uabmc.edu

Accepted for publication August 31, 2017.

\section{SURVEY RHEUMATOLOGY}

\section{MATERIALS AND METHODS}

Participant selection. A convenience sample of US rheumatologists was invited by e-mail in 2014 to participate in an online survey focused on RA management attitudes and treatment patterns. Rheumatologists were identified using a custom database maintained by the authors (JC) over the last decade, curated from personal contacts and collaborations. As part of the invitation, rheumatologists were randomized to receive $\$ 0, \$ 20$, or $\$ 40$. The survey took about $10 \mathrm{~min}$; consent was implied, conditional on participation. For those who did not initially respond, a reminder was e-mailed 1 month later. Individuals were rerandomized to be offered the same incentive or \$20 more.

Survey content. The 26-question survey solicited information regarding use of quantitative measurement in RA and related attitudes. Rheumatologists were classified as metric physicians (the main independent variable) if they self-reported that they "formally collected a disease-specific activity measure [e.g., Clinical Disease Activity Index (CDAI), Health Assessment Questionnaire (HAQ)] at every visit in RA patients." The survey also presented 3 simulated patient case scenarios to ascertain whether metric versus nonmetric physicians approached RA management similarly. These 3 cases described comparable patients, all with moderate disease activity, but provided varying amounts of quantitative information. For each case, physicians were asked whether they would escalate RA treatment.

Statistical analysis. Responses from physicians no longer in practice (e.g., retired, employed by industry) were excluded. Descriptive statistics and multivariable logistic regression was used to compare characteristics of metric versus nonmetric physicians. Survey responses were compared with 2 similar surveys deployed in $2005^{5}$ and 2008 . While the same source population was surveyed for each, not all physicians remained eligible over time; therefore, results were described as 3 serial cross-sectional surveys. Data from the 3 scenarios were analyzed using generalized estimating equations to evaluate the likelihood of treatment escalation, accounting for the clustered character of the data. Our study was governed by the local institutional review board.

Personal non-commercial use only. The Journal of Rheumatology Copyright $\odot$ (2018. All rights reserved 


\section{RESULTS}

Characteristics of survey respondents. We sampled 1918 rheumatologists, and the response rate after the first e-mail invitation for those randomized to no compensation was $13.5 \%$, lower than for rheumatologists randomized to $\$ 20$ $(17.4 \%, \mathrm{p}=0.05)$ or $\$ 40(19.8 \%, \mathrm{p}=0.003$, Supplementary Figure 1, available with the online version of this article). Across all groups, the response increased by $7.1 \%$ with a second invitation, yielding an overall response rate of $26 \%$ $(\mathrm{n}=495)$. After excluding surveys from nonpracticing physicians $(n=9)$ and those who left key questions blank $(n=47)$, the effective sample size was 439 , representing 255 metric physicians (58\%) and $184(42 \%)$ nonmetric physicians. Overall, 44\% responded that they "always practiced in a 'treat-to-target' manner," and nonmetric physicians were no less likely to report this than metric physicians. Rheumatologists in a group rheumatology practice were most likely metric physicians, as were those who reported that they used tumor necrosis factor inhibitor (TNFi) therapy for $>50 \%$ of their RA patients (Table 1). After multivariable adjustment, multiphysician rheumatology practice (OR $2.26,95 \%$ CI 1.09-4.69, referent to academic medical practice) and more frequent use of TNFi therapy (OR 1.69, 95\% CI 1.10-2.61) were the only factors significantly associated with being a metric physician, although there was a trend that older physicians were less likely to be metric physicians (OR $0.78,95 \%$ CI $0.53-1.16$ for age $>60 \mathrm{vs} \leq 60 \mathrm{yrs}$ ).

The quantitative tools used at most RA office visits were the HAQ and variants (e.g., Multidimensional HAQ, modified HAQ), and the Routine Assessment of Patient Index Data 3 (RAPID3; Figure 1) ${ }^{6}$. The CDAI (17.5\%) and the 28-joint Disease Activity Score (DAS28; 15.7\%) were less frequently used, as was the multibiomarker disease activity test $(12.8 \%)$. In total, $35.3 \%$ reported that they would not use

\begin{tabular}{|c|c|c|c|}
\hline Variables & $\begin{array}{l}\text { Physicians Who } \\
\text { Measure Quantitatively, } \\
\text { n }=255\end{array}$ & $\begin{array}{l}\text { Physicians Who Do Not } \\
\text { Measure Quantitatively, } \\
\qquad \mathrm{n}=184\end{array}$ & $\mathrm{p}$ \\
\hline \multicolumn{4}{|l|}{ Physician characteristics and practice patterns } \\
\hline Age, yrs, mean (SD) & $56.7(9.8)$ & $57.8(9.9)$ & 0.20 \\
\hline Male & 73 & 72 & 0.85 \\
\hline \multicolumn{4}{|l|}{ Practice setting, $\mathrm{n}$ physicians } \\
\hline Academic & 24 & 23 & \multirow[t]{5}{*}{0.005} \\
\hline Solo practice & 18 & 28 & \\
\hline Rheumatology group & 29 & 15 & \\
\hline Multispecialty group & 22 & 20 & \\
\hline Other & 11 & 10 & \\
\hline$>20$ RA patients seen per week & 60 & 54 & 0.20 \\
\hline \multicolumn{4}{|l|}{ Yrs in rheumatologic practice } \\
\hline$\leq 20$ & 35 & 33 & \multirow[t]{3}{*}{0.54} \\
\hline $21-30$ & 36 & 33 & \\
\hline$>30$ & 30 & 35 & \\
\hline Use TNF inhibitors for at least $50 \%$ of RA patients & 76 & 66 & 0.02 \\
\hline \multicolumn{4}{|l|}{$\begin{array}{l}\text { How many TNF inhibitors must a patient fail before } \\
\text { you choose another MOA? }\end{array}$} \\
\hline Exactly 1 & 31 & 26 & \multirow[t]{4}{*}{0.22} \\
\hline 2 & 65 & 73 & \\
\hline $3+$ & 1 & 2 & \\
\hline None; non-TNF MOA biologics are my first line & 1 & 2 & \\
\hline \multicolumn{4}{|l|}{ Beliefs about treating to target and RA patient outcomes } \\
\hline Doesn't believe in "treat-to-target hype" & 14 & 42 & $<0.01$ \\
\hline \multicolumn{4}{|l|}{ What fraction of your RA patients achieve remission? } \\
\hline$<20$ & 20 & 17 & \multirow[t]{4}{*}{0.90} \\
\hline $20-<30$ & 20 & 20 & \\
\hline $30-<50$ & 24 & 24 & \\
\hline$\geq 50$ & 37 & 39 & \\
\hline \multicolumn{4}{|c|}{ What fraction of your RA patients achieve low disease activity? } \\
\hline$<50$ & 25 & 22 & \multirow[t]{4}{*}{0.73} \\
\hline $50-<60$ & 14 & 13 & \\
\hline $60-<80$ & 32 & 35 & \\
\hline$\geq 80$ & 29 & 31 & \\
\hline
\end{tabular}

Some column totals may not sum exactly to $100 \%$ because of rounding. RA: rheumatoid arthritis; TNF: tumor necrosis factor; MOA: mechanism of action.

Personal non-commercial use only. The Journal of Rheumatology Copyright (C) 2018. All rights reserved. 


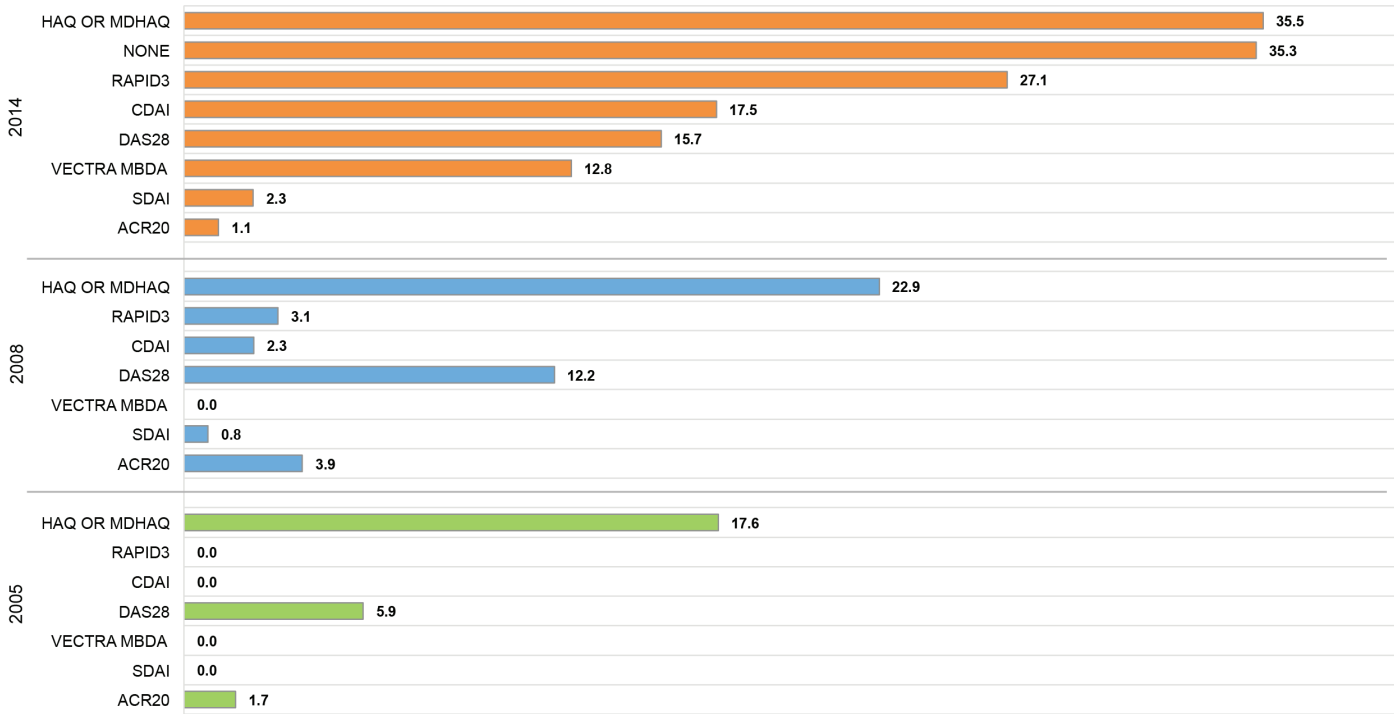

Figure 1. Metrics used by rheumatologists for patients with active rheumatoid arthritis, as self-reported in 2014, 2008, and 2005 surveys. Data were taken from all physicians in survey sample. (MD)HAQ: (Multidimensional) Health Assessment Questionnaire; RAPID3: Routine Assessment of Patient Index Data 3; CDAI: Clinical Disease Activity Index; DAS28: 28-joint Disease Activity Score; MBDA: multibiomarker disease activity; SDAI: Simplified Disease Activity Index; ACR: American College of Rheumatology.

any formal, quantitative measurement tool to assess and manage an RA patient with active disease. Among those physicians, history, physical examination, and clinical experience were typically cited as the methods used to assess and manage patients with RA. Across the 2005, 2008, and 2014 surveys, use of quantitative metrics increased over time for all measures, including $\operatorname{HAQ}(17.6 \%, 22.9 \%$, and $35.5 \%)$, CDAI $(0 \%, 2.3 \%$, and $17.5 \%)$, and RAPID3 $(0 \%, 3.1 \%$, $27.1 \%)$.

The reasons reported by rheumatologists for measuring quantitatively or not included perceptions that measurement facilitated clinical care $(76.1 \%)$ and specifically, medical decision making (62.7\%). Measurement tools were felt to be simple and useful (48.2\%), and were helpful for satisfying quality-reporting program requirements $(41.2 \%$, Table 2$)$. Reasons reported for not measuring included the process being too time-consuming (62.5\%) and not efficient electronically $(34.8 \%)$. Less common was the sentiment that quantitative measurement was not needed to support care (29.3\%). Results from the case scenarios (Supplementary Table 1, available with the online version of this article) showed that providing more quantitative information resulted in a 1.5 - to 3.7-fold greater likelihood that the rheumatologist said that they would change or add disease-modifying antirheumatic drugs/biologics. Aggregating results across all 3 cases, metric physicians were 1.4 times $(95 \%$ CI $1.0-1.8, \mathrm{p}<0.03)$ more likely to change treatments versus nonmetric physicians.

\section{DISCUSSION}

In our US survey, $58 \%$ of rheumatologists self-reported using quantitative RA measurement tools at most visits. The HAQ and RAPID3 were most commonly used, followed by the CDAI, and use of all measures increased over the 10-year period covered by the 3 surveys. The reason most commonly given for valuing RA measurement was that the information

Table 2. Reasons physicians do or do not routinely perform quantitative assessment. Values are $\mathrm{n}(\%)$.

\begin{tabular}{lc}
\hline What motivates you to measure RA metrics routinely? & $\mathrm{n}=255^{*}$ \\
To facilitate/improve clinical care & $194(76.1)$ \\
To incorporate into medical decision making & $160(62.7)$ \\
Easy, simple, and useful & $123(48.2)$ \\
For Medicare PQRS or other quality-reporting programs & $105(41.2)$ \\
Participation in a research registry & $47(18.4)$ \\
Insurance companies require it & $47(18.4)$ \\
Treat-to-target trials (TICORA, BeST) show & \\
impressive data & $70(27.5)$ \\
Other & $21(8.2)$ \\
Why don't you collect RA metrics routinely? & $\mathrm{n}=184^{*}$ \\
Takes too much of my time & $115(62.5)$ \\
Not available on my EHR & $64(34.8)$ \\
Don't need them & $54(29.3)$ \\
Too many to choose from & $32(17.4)$ \\
Not required by payors & $32(17.4)$ \\
Value is unproven & $31(16.8)$ \\
Requires laboratory measures (CRP or ESR) & $26(14.1)$ \\
Too difficult or complex & $23(12.5)$ \\
Language/communication difficulties (elderly, & \\
Spanish-speaking, etc.) & $20(10.9)$
\end{tabular}

*Responses not required nor mutually exclusive; row totals do not sum to $100 \%$. PQRS: physician quality reporting system; TICORA: tight control of rheumatoid arthritis; BeST: Behandel Strategieën; RA: rheumatoid arthritis; EHR: electronic health record; CRP: C-reactive protein; ESR: erythrocyte sedimentation rate. 
collected was useful to facilitate clinical care. On the other hand, the most commonly provided reason for not measuring was related to logistics. Physicians were not opposed to measuring, but they lacked the time and electronic tools to do so efficiently. Results from 3 simulated case scenarios showed that providing additional quantitative disease activity information led to more guideline-concordant treatment changes for RA patients who had moderate disease activity, regardless of whether the rheumatologist was a metric physician.

Comparative information for the proportion of physicians in other settings measuring RA quantitatively is scant. An online survey sent to a sample of US rheumatologists (14\% response, $\mathrm{n}=125)$ found that the DAS28 (37\%), RAPID3 (33\%), and CDAI (21\%) were used relatively frequently ${ }^{7}$. Results from that study ${ }^{7}$ and ours suggests that Canadian and international rheumatologists quantify RA disease activity more often than their US counterparts ${ }^{8,9}$.

As noted, results from registries cannot easily serve to provide information because quantifying disease activity and function is intrinsic to most physician-based registries (e.g., Corrona $)^{10}$. The American College of Rheumatology's (ACR) Rheumatology Informatics System for Effectiveness (RISE) registry extracts data routinely collected in rheumatologists' electronic health record (EHR) systems ${ }^{11}$. In 2016, $55 \%$ of patients with RA had their disease activity measured quantitatively ${ }^{12}$, similar to our results and that from an Australian report ${ }^{13}$. However, these results are constrained by important generalizability concerns: rheumatologists participating in RISE are early adopters and may be more likely to measure disease activity to satisfy quality reporting metrics tied to financial incentives.

Logistical issues were the main barriers to physicians not measuring quantitatively, and methods and tools to efficiently collect data from patients (with or without additional physician information) are needed. Several examples of electronic tools to satisfy this need have been described $^{14,15,16}$. While a feature-rich electronic system provided by an EHR vendor would be an attractive solution, few, if any, presently exist. A standalone disease activity measurement system that can be integrated with the EHR using informatics standards that foster interoperability (e.g., Health Level 7 International, Fast Healthcare Interoperability Resources) may be particularly attractive for many settings ${ }^{14}$.

Providing rheumatologists an incentive of $\$ 20-\$ 40$ yielded a roughly $5-10 \%$ higher survey response rate. A second contact 1 month later boosted response by about $7 \%$, although further increasing the incentive by $\$ 20$ had minimal effect. Although lower than desired, our response rate of $26 \%$ is typical for an online physician survey ${ }^{17}$. Prior surveys conducted by the authors and by others published in medical literature generally find that response rates to a physician survey range from $13 \%{ }^{18}$ to $35 \%{ }^{19}$. The survey topic, credibility of the authors, and followup reminders increase response ${ }^{19}$, as do incentives ${ }^{20}$.
Notable features of our study include conducting 3 serial surveys over time involving many US rheumatologists with similar demographics and practice settings to the ACR's membership (J. Martin, ACR Membership Specialist, personal communication 2017). However, we recognize that because of the relatively low (albeit typical) response rate, our results may not be generalizable to other rheumatologists. It is also possible that survey respondents may have had greater interest in the topic and are more likely to measure quantitatively. If so, our findings represent a "best case scenario" regarding the proportion of US rheumatologists measuring quantitatively.

These results show that for many rheumatologists, quantitative measurement in RA is not an essential facet of routine care. Encouragingly, US rheumatologists seem agreeable to obtain quantitative data from their patients if only it were made more efficient to collect, ideally through electronic means. Developing and deploying embedded EHR-based tools, or standalone systems integrated with EHR, would serve this goal and facilitate evidence-based RA management, leading to more optimal quality of care. For future research, it may be useful to examine outcomes in patients with RA using quantitative measures, particularly when qualitative physician judgment deems them to be "doing well" but whose assessment is discordant with clinical remission or low disease activity.

\section{ONLINE SUPPLEMENT}

Supplementary material accompanies the online version of this article.

\section{REFERENCES}

1. Smolen JS, Breedveld FC, Burmester GR, Bykerk V, Dougados M, Emery P, et al. Treating rheumatoid arthritis to target: 2014 update of the recommendations of an international task force. Ann Rheum Dis 2016;75:3-15.

2. Singh JA, Saag KG, Bridges SL Jr., Akl EA, Bannuru RR, Sullivan MC, et al. 2015 American College of Rheumatology guideline for the treatment of rheumatoid arthritis. Arthritis Rheumatol 2016;68:1-26.

3. Smolen JS, Landewe R, Bijlsma J, Burmester G, Chatzidionysiou K, Dougados $\mathrm{M}$, et al. EULAR recommendations for the management of rheumatoid arthritis with synthetic and biological disease-modifying antirheumatic drugs: 2016 update. Ann Rheum Dis 2017;76:960-77.

4. Anderson J, Caplan L, Yazdany J, Robbins ML, Neogi T, Michaud $\mathrm{K}$, et al. Rheumatoid arthritis disease activity measures: American College of Rheumatology recommendations for use in clinical practice. Arthritis Care Res 2012;64:640-7.

5. Cush JJ. Biological drug use: US perspectives on indications and monitoring. Ann Rheum Dis 2005;64 Suppl 4:iv18-23.

6. Pincus T, Swearingen CJ, Bergman M, Yazici Y. RAPID3 (Routine Assessment of Patient Index Data 3), a rheumatoid arthritis index without formal joint counts for routine care: proposed severity categories compared to disease activity score and clinical disease activity index categories. J Rheumatol 2008;35:2136-47.

7. Glauser TA, Ruderman EM, Kummerle D, Kelly S. Current practice patterns and educational needs of rheumatologists who manage patients with rheumatoid arthritis. Rheumatol Ther 2014;1:31-44.

8. Haraoui B, Bensen W, Thorne C, Wade J, Deamude M, Prince J, et al. Treating rheumatoid arthritis to target: a Canadian patient survey.

Personal non-commercial use only. The Journal of Rheumatology Copyright @ 2018 . All rights reserved. 
J Clin Rheumatol 2014;20:61-7.

9. Haraoui B, Smolen JS, Aletaha D, Breedveld FC, Burmester G, Codreanu $\mathrm{C}$, et al. Treating rheumatoid arthritis to target: multinational recommendations assessment questionnaire. Ann Rheum Dis 2011;70:1999-2002.

10. Kremer JM. The CORRONA database. Autoimmun Rev 2006; 5:46-54.

11. Yazdany J, Robbins M, Schmajuk G, Desai S, Lacaille D, Neogi T, et al. Development of the American College of Rheumatology's rheumatoid arthritis electronic clinical quality measures. Arthritis Care Res 2016;68:1579-90.

12. Yazdany J, Bansback N, Clowse M, Collier D, Law K, Liao KP, et al. Rheumatology Informatics System for Effectiveness: a national informatics-enabled registry for quality improvement. Arthritis Care Res 2016;68:1866-73.

13. Taylor A, Bagga H. Measures of rheumatoid arthritis disease activity in Australian clinical practice. ISRN Rheumatol 2011;2011:437281.

14. Yen PY, Lara B, Lopetegui M, Bharat A, Ardoin S, Johnson B, et al. Usability and Workflow Evaluation of "RhEumAtic Disease activitY" (READY). A mobile application for rheumatology patients and providers. Appl Clin Inform 2016;7:1007-24.
15. Newman ED, Lerch V, Billet J, Berger A, Kirchner HL. Improving the quality of care of patients with rheumatic disease using patient-centric electronic redesign software. Arthritis Care Res 2015;67:546-53.

16. Newman ED, Lerch V, Jones JB, Stewart W. Touchscreen questionnaire patient data collection in rheumatology practice: development of a highly successful system using process redesign. Arthritis Care Res 2012;64:589-96.

17. Dykema J, Jones NR, Piche T, Stevenson J. Surveying clinicians by web: current issues in design and administration. Eval Health Prof 2013;36:352-81.

18. Scott A, Jeon SH, Joyce CM, Humphreys JS, Kalb G, Witt J, et al. A randomised trial and economic evaluation of the effect of response mode on response rate, response bias, and item non-response in a survey of doctors. BMC Med Res Methodol 2011;11:126.

19. Cunningham CT, Quan H, Hemmelgarn B, Noseworthy T, Beck CA, Dixon E, et al. Exploring physician specialist response rates to web-based surveys. BMC Med Res Methodol 2015;15:32.

20. Reinisch JF, Yu DC, Li WY. Getting a valid survey response from 662 plastic surgeons in the 21st century. Ann Plast Surg 2016;76:3-5. 